\title{
Implementing and Assessing Student Performance Skills and Learning: A Policy Role-Playing Exercise
}

\author{
Patricia OReilly, ${ }^{1, *}$ \\ ${ }^{1}$ Dept. of Politics and Public Administration, Ryerson University, Toronto, Canada \\ *Correspondence: Dept. of Politics and Public Administration, Ryerson University, Toronto, \\ Canada_E-mail: poreilly@ryerson.ca
}

Received: January 25, 2013 Accepted: February 17, 2013 Published: February 27, 2013

doi:10.5296/ije.v5i1.3137ＵRL: http://dx.doi.org/10.5296/ije.v5i1.3137

\begin{abstract}
Performance skills are important in all public institutions and workplaces, and they play a central role in social engagement and leadership. The ability to perform effectively and intelligently requires individual skills that improve with practice and guidance. We ask our students to perform in the classroom on a regular basis, and they are both formally and informally evaluated for this. However, we spend little time thinking about how performance could be better designed into our post-secondary education. This paper looks at the literature findings related to both performance skills and the utility of role playing and suggests ways to incorporate student performance development into public policy studies. A three-stage process which can be broken down into smaller units for easier application is provided and analyzed in the paper. It also introduces the importance of what the author calls 'performance learning' for our post-secondary social science programs, with a focus on developing better student understanding of the importance of power, discourse and informal relations in social studies. Preliminary findings from policy student groups utilizing these methods are also presented.
\end{abstract}

Keywords: performance skills; performance learning; implementing and assessing; role playing; triage; negotiation; debate; journal writing; power; discourse; informal relations; policy studies 


\section{Introduction}

Instructors constantly strive to accurately assess students' learning, that is, the knowledge students have gained in a subject. At the post-secondary level, their memory and ability to reason are tested and examined repeatedly. However, the performance component of knowledge is often not emphasized and only weakly assessed. Performance is here referred to as the ability to orally present and/or argue or debate your ideas to or in a group. Performance skills are important in all public institutions such as the university or workplace, and they play an important role in social engagement. Acquiring the skills for public speaking and presentations is a useful and practical part of learning, but the lack of attention in the teaching and learning literature to the development and assessment of performance skills in post-secondary social science education means we are undervaluing an important element of learning - one that post-secondary students themselves value (Cavanagh, 2011). A scan of the teaching and learning literature shows very little reference to performance skills of students as performance rather than as knowledge acquisition (Lai, 2011).

Learning through performance ought to be encouraged, assisted and rewarded. It is a reality for both the student and the graduate. In the classroom or tutorial there is always both informal and formal evaluation of students' performances. In the public sphere, students and instructors share in the fact that all adults need to "perform" in regular public engagement. There are performance skills sets that are useful to this social and political interaction. Educational institutions need to teach these skills to prepare their graduates for the workplace - especially when many full-time jobs begin as short-term contract jobs and those who "perform" best are more likely to be offered the full-time jobs. The ability to perform effectively and intelligently requires individual skills such as personal presentation and professional comportment, clear articulation, systematic revelation of one's ideas, and ease of intellectual exchange. These are the kinds of skills that tend to improve with practice and guidance, as well as help develop influence and leadership (Rackaway \& Goertzen, 2008, p. 330). As instructors we sometimes forget that despite all their education, even graduate students may not have developed basic professional skills. We at the post-secondary level could learn from the training of earlier-level education teachers where classroom performance is proven to be enhanced by such non-academic factors as recognition of the role of emotions in learning (Timostsuk \& Ugaste, 2012) and face-to-face performance feedback from instructors (Thurlings, Vermeulen, Kreijns, Bastianens \& Stijnen, 2012).

Another level at which performance is important to the education of the student is that of improved understanding of the nature of our social and political environment. That is, while learning through performance is important; learning about performance is also important. In order to better understand social and political interaction, students would do well to understand the use of performance in the institutions and discourse of the public sphere. Although the latter is being studied more and more in the social sciences - in for example, discourse analysis - the former is relatively understudied; and the importance of performance per se is not often considered in the social sciences. In Political Science/Studies in North American, for example, there are many textbooks that document and discuss the institutions, actors and processes of politics, but there are few studies that show the underlying informal 
human relations and emotions that drive interactions in the formal systems of governance, despite their importance to politics (Johns, O'Reilly \& Inwood, 2007). Politicians, like any public actors, relate to each other and to their public. That is, they perform.

When students themselves experience the limits of process and subjectivity through performance, they understand it better. In one of my policy courses, an undergraduate student reporting on our classroom performance exercises, had this to say

I always knew that the political system and policy-making were complex, but my understanding of these processes was largely academic...In essence, I have a good understanding of how the system works and who the major and minor players in it are, but I really had no concept of how it feels to be a part of it. The policy exercises (we did in class) really helped open my eyes as to why a policy often ends up radically different from when it was first envisioned.

Through the use of more structured forums for performance learning, students can both enhance their own professional performance skills and gain a better understanding of the complex messy nature of public social engagement - as it is practiced. With this in mind, this paper looks at some of the means by which we might organize, monitor and evaluate our students' performances in political exercises in order to encourage knowledge and development of performance skills and performance learning. First, it looks at the importance of encouraging performance skills in students and provides simple assessment techniques for evaluating student presentations and classroom or tutorial debates. Second, it provides a three-part policy exercise which could be used either individually or in a progressive developmental process to enable students to enhance their interactive performance skills and to better understand the limitations encountered by policy makers. Third, it discusses some means for instructor assessment of students' performance throughout the policy exercise, as well as students' understanding of the role of performance in politics. And fourth, this paper presents some early finding and conclusions from the author's use of the policy exercises in various political studies courses over several years.

\section{Encouraging Student Performance Skills and Performance Learning}

Whether or not we make much note of it, performance is an important aspect of any post-secondary educational classroom and tutorial experience. Social studies and humanities courses have a considerable amount of informal discussion and debate. Classroom lectures often include Socratic exchange between the instructor and those students who choose to engage with questions or ideas in the classroom; and informal debates among the students are also encouraged by some instructors. However, the lecture format tends to ensure that these classroom exchanges are ad hoc and limited in nature. Tutorials attached to lectures are set up as a means to allow for more elaborate and continuous discussion and debate among the students, but, this format is generally not very structured and it is left up to the (often inexperienced) tutorial leader to run a fairly informal session that may vary considerably from tutor to tutor. 
Students are asked to speak, discuss, debate and present; but although it is often encouraged, it is not so often systematically organized, monitored and evaluated with feedback to encourage student improvement and development in this skill. Where participation is graded it is often done so more for content than performance per se. Even when performance skills are directly assessed and graded such as in mandatory slide presentations, they are rarely taught or weighted heavily in the final grade. This signal from the instructor means the students themselves are not always encouraged to perform well - many participate reluctantly. In a large classroom setting students are often nervous about how they are perceived by their peers as well as the instructor, and need encouragement to learn performance skills such as how to speak and present in front of groups. Adding an element of performance assessment provides the instructor with both the excuse to decrease the volume of input from the overly enthusiastic student and increase the input of the more reserved student.

There are two things to keep in mind here: one, both individual and collective student performance already affects the quality of student learning whether or not we focus on it; and two, when students come together and undergo the pressures of the institutional learning environment, they are under both hierarchical student-to-instructor pressure and student-to-student peer pressure. At the most obvious level, the classroom or tutorial environment is altered by student engagement, either positively or negatively. As any instructor or student knows, the discussion and debate can be elevated by the performance skills of a few good students, or it can be lowered by weaker but highly vocal students. In either case the environment may discourage the more timid students from speaking. If the instructor maintains a degree of control over student participation, this can improve both quality and fairness.

At a more hidden level, there are subtle pressures related to performance in the classroom or tutorial. Instructors are making conscious and unconscious judgements about a student's intellectual and social abilities when listening to student responses and engagements during the most simple classroom exchanges. Students are right to be concerned that classroom performance is noticed by the person who will be evaluating their course learning. There is a hierarchy here. There is also considerable peer pressure among students in any classroom or discussion group, just as there is among academics themselves. It is better, I would argue, to recognize this rather than ignore it. In this way teaching exercises and techniques can be used to counter these pressures while downplaying the disadvantages and enhancing the advantages of the oral exchange and debate in student-to-instructor and student-to-student exchange. It would also enhance fairness since students who are uncomfortable with performance skills are those who suffer most from the open, ungraded discussion.

There are various simple means by which an instructor can allow for active performance in the classroom and these can be monitored with instructor feedback and grading. For example, simple classroom presentations and debates can be set up with performance in mind. But in order to teach students more fully about the nature of their own and broader institutional performance skills an instructor needs to set up a more formal means of playing out and monitoring these skills as well as and providing feedback for improvement - not unlike those advocated by professionals-in-training through some sort of service learning (Gleason \& 
Violette, 2012, p. 280) or those used for training teachers by utilizing keywords to prevent learner overload during instructor feedback (Coninx, Kreijns \& Jochems, 2012, p. 11).

A useful method of active performance in the classroom which is used throughout the social sciences is that of role playing - which has the added advantage of including and coaching the more reserved students, such as those who are reluctant participators for cultural reasons (Chunlei \& Han, 2010, p. 81; Micari \& Drane, 2011). The education literature on role playing and simulations, although weighted toward the positive, is somewhat ambiguous on its benefits (Chad, 2012, p. 23). Analysis suggests they increase student interest, enthusiasm, sense of control over learning, and development of empathy (Dougherty, 2003). Some say they increase political knowledge (Baranowski, 2006; Kahn \& Perez, 2007), develop critical thinking and logical reasoning (Hayati, 2006; Smith \& Boyer, 1996), increase retention of knowledge (Cherney, 2008; Smith \& Boyer, 1996), and decrease levels of cynicism (Lay \& Smarick, 2006). Others note that they improve students' public speaking abilities and negotiation skills, as well as their capacity to critically analyze their own positions on issues (Fliter, 2009) or ethical dilemmas (Rackaway \& Goertzen, 2008).

Conversely, some analysts have shown little difference of increased learning or knowledge of the subject taught through the use of simulations and experiential learning (Krain \& Lantis, 2006; Powner \& Allendoerfer, 2008). (Although this is countered by methodologists such as Chad who suggests that these results may be more attributable to poor technique on the part of the simulation designers than to student efforts (Chad, 2012).) It is also, I would argue, important to note that this literature tends to focus on the measurement or evaluation of student learning with the use of these exercises. It is then compared to learning in standard teaching forums, generally through comparative test results of total acquired knowledge. While this may be a useful exercise to prove a point, it is to some degree missing the point. An additional approach to teaching that only supplements a strongly traditional education for students need not be "better than" standard academic teaching methods currently used in the field to merit use. Even if it were "less than" in terms of rote knowledge taken away from a social science course that will in all likelihood be outdated before long-certainly in political knowledge-the fact that it might alter the traditional routine of exams and essay writing for students and generate such benefits as enthusiasm, empathy, a focus on ethics and decreased cynicism would make it worthy of pursuit.

Essays are a good tool for the development of critical thinking skills, but as others have also noted, there are other means and other tools to develop "higher order thinking skills" in students (Cherney, 2008; Rackaway \& Goertze, 2008), especially where understanding of multi-dimensional and complex relations is required (Grove, 2005). It is notable that the most extensive use of role playing and simulations in political science is in International Relations where negotiations and diplomacy play such a key role in political outcomes (Chasek, 2004). It is easier to teach this sort of dynamic to young adults through role playing.

I would argue there is value-added by experiential learning even if it is only as good as the standard teaching formats measured by standard learning measurements. These debates over the measured outcomes are missing a significant point about the importance of performance 
learning by students. While standard learning outcomes are clearly important to teaching, verbal engagement or the performance aspects of educational exercises are also important, and as I argue here, the two are linked in the real world of social and political engagement. Policy and legislative output, for example, is not the product of knowledge alone; it is developed through one-on-one interpersonal interaction during set processes within institutions and among actors engaged in ongoing rhetorical and power relations. The educated student would do well to better understand these dynamics.

\section{Three-Stage Policy Exercise}

For anyone interested in teaching about public performance and the role it plays in our social and political processes and outcomes through experiential learning, a series of graduated participation forums that highlight both process and content is useful. Here the students learn more than in a standard lecture or tutorial about the structuring of group discourse and what this does to political or policy content. Over the course of three weeks a series of expanding forums may be used: starting out as one-on-one and then getting larger and more complex in both process and content.

This exercise may be used to illustrate different social or political interactions such as structural, administrative or policy dynamics (redesigning institutional processes, enhancing institutional/group accountability and ethics, or producing policy and/or policy analysis). Here the example of a public policy debate and some of its common forums will be used.

Preparation for the policy exercise includes an assigned or student-chosen jurisdiction and policy issue, e.g., a nation-state dealing with climate change, plus an assigned political role for each student, e.g., the national leader, various party members, members of a policy network, etc. (Hereafter, the example of political parties will be used.) Research guidance is given, and preferably illustrated, in class. Media presentations of legislative debates, journalist scrums or political or policy issue debates that feature cross-party discussions of political or policy issues are good tools for this type of classroom learning. This allows for a better understanding by the students of the actors and institutions involved, as well as the policy debates common to the chosen policy field. It also allows for illustration of the use of rhetoric and argument, as well as the use of content avoidance as a political tool. These are strategies the students may wish to employ in their own discussions and debates.

The first week of the Three-Stage exercise is called the Triage Stage. Here each student comes to class with a personal triage list that moves from the most to least important issues in the selected policy area. Students are told explicitly to use their own personal policy preferences here, but to also research their political role so that they understand how the person they will later represent would think about the policy. When the exercise begins the students are put into groups of two, then four, then eight, and so on, respectively, depending on class size. Each student must begin by explaining and defending her or his original triage list to the discussion group (of two) and then come to an agreement on a new list to take to the next level (of four), and so on until the full group has one triage list. This entails 
considerable discussion, debate and retreat. Power dynamics, persuasion and knowledge differentials among the students begin to show up here, since they are forced to agree on one list in the end.

The second part of the Triage stage, then, asks the students to repeat the first exercise, this time acting out their assigned political role within their own political party, and again producing one triage list - to be used in the next stage of the exercise. By representing a political actor, they are forced to move beyond their personal perspective to look at the likely output of the political actors involved. It provides the opportunity to see how process and hierarchy affects output since the party members range in power. It also provides an illustration of how ideas, relations and emotions can shape or even subvert a seemingly straightforward process. In these exercises both the interpersonal and institutional world is brought in to demonstrate the effects they can have on politics and policy making.

Once a final single triage list is produced by each party in the class, they are ready to enter the Negotiation Stage held the following week, preferably in an informal setting. The time lapse allows the students to assimilate the triage experience, record their impressions (more below in Assessment section), and engage in further research with the members of their own party. At the negotiations, each party has a central table where the party leader coordinates activities, sending out sets of students to negotiate with the other parties. Blank tables with headings are provided for students to keep track of the negotiations. In the role playing, the governing party group is looking for backers for the triage they will be pushing during the final policy debate stage. Other groups are deciding whether or not to back those in power as well as which groups or individuals they might be able to bring on board in order to oppose the governing party during the policy meeting. The students then report back, and at the end of the session each party leader meets individually with each of the other party leaders to debate and negotiate positions. The results of these negotiations are known only within each party and will be used to build its strategy for the more formal debate the following week. The negotiation exercise helps reveal the dynamics of political communication, debate and negotiation. It also illustrates to the students the "back room" strategies and deal making of the real pre-meeting political dynamics that occur prior to major policy meetings/debates in, for example, the legislature, committee system, executive caucuses, or institutions of federalism.

The final stage of the learning exercise, the Debate Stage, is where a full class debate is held and a vote taken on a final policy "to do" list. If using political parties, this can be a legislative debate and vote of the full legislature or house. The students' task here is further develop performance skills, and to demonstrate political and policy knowledge. Each student brings his or her research summary notes, party triage list and negotiation tables, and another blank table with headings is provided to make quick notations during the debate. Prior to the debate, each party also prepares a brief opening statement of their policy position. After the opening statements, the floor is open to debate and it is up to the individual students and their group to put forth their best arguments and counter-arguments to the policy choices proposed. The competitive environment means it moves along at a good pace, since the students are eager to demonstrate all the policy research they have in front of them. As one student put it, 
"When the debate occurred, I learned that you really had to stay on your toes and think quickly in order to rebut." At the end of the session either consensus is reached on a number of issues or a vote is held and the majority wins. The results of the vote are recorded in the session and can then be used in the student's final journal entry.

The debate exercise advances the students' understanding of communication, debate, and negotiation, only this time it is in a formal institutional setting where there are rules of procedure, time limits, and hierarchies of authority. Performance skills play a role here as well. This is enhanced if the simulated institutional process is one which is open to the public, such as a House Question Period, where the dynamics of political language and rhetoric aimed at the public through the media can be demonstrated. Of course, the debate also offers students the opportunity to demonstrate their policy and political knowledge - or content knowledge rather than process or performance knowledge.

Any of these three stages could be used independently, but there is an advantage to using all three and to using them in succession. Education experiments have shown that although some students start out with trepidation about new modes of learning, this is often overcome as the exercise progresses (Frederking, 2005, p. 391). The staged approach allows the student to build up gradually toward the more pressured performance forum of the full debate. They begin in the less formal communications and debate sessions without too much pressure, since the instructor is not focused solely on them, and the group dynamics are still small. But as the role playing exercises progress, they are under increasing hierarchical pressure and peer pressure to perform. The staged approach also takes the students from their original personal policy preferences through a simulated institutional process: from the internal informal process of the triage, to the external informal process of the negotiations, to the external formal process of the policy making debate. Students learn: how this process alters their personal policy list; what the informal sphere does to policy content; and what the formal rules of an institution allow in the development of public policy. These things rarely discussed or not fully understood out of textbooks.

\section{Assessing Student Performance Skills and Performance Learning}

As others have noted, evaluating student performance can be difficult (Hertel \& Millis as cited in Austin, McDowell \& Sacko, 2006). In the early stages of the learning exercise presented here, the students are merely performing for each other and occasionally for the instructor when close by. The exchanges are being watched and therefore informally "assessed," (under hierarchical and peer pressure) but they are not yet being formally graded. To move toward performance assessment, one option is to periodically stop the process and randomly select student groups to demonstrate to the rest of the class the dynamics of their discussion. Assessment can include some form of scoring or grading. Some education authors recommend that instructors engaged in experiential learning such as using role playing simulations use scoring or grading rubrics (Austin et al., 2006) or course marking schemes designed to accommodate both positive and negative performance (Schaap, 2005). Austin, McDowell and Sacko suggest that utilizing a scoring rubric in simulations is helpful for 
several reasons. First, having a clearer idea of what criteria are being marked and knowing the instructor's expectations will allow students to perform better. Secondly, utilizing a grading rubric based upon different attributes of the simulation (rather than grading holistically) allows students to see their performance in terms of areas of strength/weakness as opposed to simply a grade (Austin et al., 2006). This method works for smaller classes and simpler presentations, but when you have a heated debate moving rapidly or a large class it is difficult to do. Austin, McDowell and Sacko recommend video-taping the debate elements of the simulation so that instructors can concentrate on running the proceedings and not on marking at that time. This further allows for later review of the simulation's proceedings so that the instructor can be self-evaluate what elements of the exercise worked and those that did not (2006). While this is a good suggestion, it adds considerable additional work for the instructor, and many instructors say that the extra volume of work associated with experiential learning is a key reason why they do not engage in it. For a summary of literature on barriers to instructor's use of simulations, games and role playing see Lean et al., 2006, p. 232.

For larger classes (of eighty students) a simple scoring scheme is more manageable. The student group lists that sets up the assigned roles, for example the party to which a student belong, can readily be transferred to Excel to create a table with headings that can be checked off or noted when each student speaks to the class. For example the headings "Spoke" "Quality of Research/Argument" and "Quality of Performance" can be used to keep track of a student's quantity and general quality of participation - the latter using a letter indicator of $\mathrm{H}$, M, L or P to denote a quality of high, medium, low or poor. (An earlier assignment in the course, used to build knowledge for the policy exercise, can incorporate a presentation of this kind. I often use a Minister's Briefing Note for this.) For the larger class size, this simple system is quite manageable even in a heated debate as long as the students have name plates, or provide their name when speaking. My experience with this has been that students think it is fair; in fact, some have commented they think it is fairer than other classes where their oral contributions are not being assessed systematically.

Beyond this type of assessment of oral presentation, there appears to be a strong opinion in the literature that students benefit from more structured follow-up to these types of role playing exercises. For a review see Stover 2007, p. 112 and Wheeler 2006, p. 6. Many educators recommend debriefing sessions and/or the use of student journals or reflection diaries for self-reflection on the role playing exercises (Galatas, 2006; Grove, 2005; Jones, 2008; Kahn \& Perez, 2007; Moss, 2000). As Galatas found, asking students to write reflection papers "allowed the students...to explore more fully their thoughts and perceptions of the simulation" $(2006,149)$. As a possible addition to the exercises presented here, Bolling has reported on the use of joint journals where students write entries in order, answering a set of questions set out by the instructor. This would have the added advantage that the students would be further performing for each other and the instructor. Bolling concluded "The group journal capitalizes on the influence of collaboration and engenders more careful attention to writing performance, better attitudes toward writing, and greater comprehension of course content (Bolling, 1991, p. 53-4)." One caveat might be useful: De Grez, Valcke and Roozen 
found that while role playing students tend to be positive about peer assessments, they also tend to assess themselves more highly than does the instructor (2012).

Both the de-briefing session and the journal serve as means of student reflection. They could both focus mostly on content learning, but they are also a useful tool to focus on performance learning. For the de-briefing session the instructor simply sets up a "what did we learn" set of questions and the students' verbal answers can be recorded for their use for testing in the course. However, the journal - which can be counted as one of the course assignments with accumulated research notes and tables attached - is written by each student as the stages progress. It is treated as an "intelligent diary" that records the personal and political dynamics and outcomes of the exercise. It could ask them to "talk" in their journal about i) performance dynamics and their effects on outcomes, ii) process dynamics and the limitations they placed on roles and outcomes, and iii) content dynamics which resulted in modifications to the original policy triage lists. For the graduate level, students can also be asked to relate their new understanding of the policymaking process to the theoretical debates about rationality and non-rationality in the policymaking process, with the obvious intent of enhancing their methodological understanding of the importance of discourse, informal relations and power dynamics in state and public output.

\section{Findings}

Student's journals provide a window into how they feel about performance-based activities and the process of learning they go through during an experiential exercise. On reflecting on their own and their classmates' performance dynamics and the effects these had on outcomes, students tended to display an increased awareness as time went on. With regard to their own performance, students fell across a spectrum from fear of performance to enjoyment of performance, with many more falling into the former category than the later. Many students said they found it difficult to speak in a forum and avoided it or forced themselves to do it because of the participation marks. They were unable to "jump in" to the debate because of being either too nervous or unable to adapt their ideas to the flow of the debate - even when the opportunity was set up by the instructor, few of the quieter students took advantage of it. However, many said they had begun to feel more comfortable while participating in the progressively expanding groups. They also complained that the expanding size led to more conflict and resentment as stronger personalities emerged in the debates and began to direct the group toward their own preferred outcomes. Some students expressed regret at having allowed the more vocal or passionate students to sometimes dominate the discussions, and their having acquiesced to the power of the leaders or the majority sentiment. One of the more dominant students said, "I got corrupted with power...and this caused me to have some deep reflections."

Interestingly, when asked to comment on student performance, few students commented on articulation or oral abilities. Rather they referred more to the use of rhetoric or "leadership style," the ability to think and debate "on your feet." Many commented that the exercises made them realize that knowledge alone is not enough - other people's superior performance 
skills could prevent them from getting their point across. They also noticed that informal relations were more important than they had previously understood. By engaging in the communication, negotiation and deal-making themselves, they realized not only "how it feels to be part of it" but how important ongoing relations and would be. Friendships, animosities and positions of power would matter. As one student noted, "While textbooks may make the relationship between the Prime Minister and Members of Parliament seem mechanical, in reality "it is much more difficult to be in (a position of) power." Another note, "Persistence is needed and real desire and belief in a policy helps get it through."

While the early entries to the diaries tended to be more simple and personal, the latter entries displayed increasing awareness of the combination of these personal dynamics with structure and process. For example, many students originally found it challenging to play a role if it did not fit their personal beliefs or ideology, and to see issues from other perspectives. Later they commented that they had "gained a real appreciation for the merits of some of the arguments made by the opposite end of the political spectrum." Or that they realized they might have to try and remove their own political biases if they were to work within an institution, for example, as a party member or a public servant giving policy advice to a politician. That is, they began to show awareness that what they originally saw as personal was also inherently structural or process driven.

With regard to the content requirements of their performance, students found it difficult to keep up in areas where they were not knowledgeable and this taught them "the importance of good research in both negotiations and debate." Some students who earlier commented it was difficult to "think on their feet" in a formal setting, realized it was much less problematic when they knew their subject well and had prepared the proper notes. However, they also realized, "knowledge is not enough."

Interestingly, despite all the group work done in their university education, students often made comments which indicated this had been the first time they had actually done much reflection on it. For example, one student said, "I learned that listening was important." Another, that, "I learned what it meant to work as a team" (the operative word being 'as' rather than 'with'). Others commented on their realization of such things as the importance of leadership and the difficulties in homogenizing the views of a large group and maintaining good group communication channels. Performance in a group has a "significant effect on policy outcome" one student commented. This awareness partly reflects the continuity of the staged learning process but it also shows a raised awareness of the interactions of performance, process and content dynamics and their effects on roles and outcomes. Even the most advanced students commented in their journals that they had never really understood how important all of these dynamics were to politics and policy. As one said,

In the theoretical study of policy formulation, implementation, and evaluation, diagrams and arrows depict the multifaceted nature of stakeholder interactions illustrating the policy process. The policy cycle looks relatively logical and clear-cut. What is missing for the students studying policy development theory is the thrust and parry of negotiations and the sometimes irrational nature of human choices. The 
emotion, surprising reactions, and partisan nature of political expediency are not adequately captured within a text or through a lecture... The simulation provided a unique opportunity to understand the realities of shaping policy in a legislative committee situation.

Preliminary qualitative findings related to grade scores reveal some interesting trends. In simplified earlier versions of these policy exercises which were contained in one week, neither a journal nor debriefing session were used, although it was recommended to students that they think about the lessons learned during the simulation when they studied for their final exam, which contained a question on the simulation. However, only a few of the best students in the class were incorporating the lessons from the experiential learning into their answers on the final exams. Therefore, an oral de-briefing session was added in class before the exam and this resulted in improved answers, but generally only from the better students in the class. Finally, the best results were attained with the incorporation of a journal with a final entry for overall reporting on the full policy exercise, and a short de-briefing session as part of a pre-exam review of the course. Simply being asked in an exam question about what they had learned about policy making from their policy exercises did not seem to offer enough time for students to translate what had occurred in the policy exercise with what they read in the standard textbook (on the policy cycles for example).

Grade records provide information on some interesting trends. I found, for example, there was a grade improvement for the same course of approximately 80 students taught over two years - once without a journal or reflection prior to an exam question about the policy making process, and once with a journal and report that asked them to reflect on what they had learned in the experiential exercises and then asked them the same exam question as the previous year's students, that is, What did the policy exercises tell you about why policy making is so difficult? Keeping in mind this is a comparison of two role playing classes, the students who had simply done the learning exercises but had not been asked to reflect on them before the exam showed little or no improvement in their overall grades over the duration of the course. That is, the A students answered this question at an A level, the B at a B level and so on. However, when the students from the class that had followed the learning exercises with a journal and report answered this question, most raised their mark for that question and thus raised their overall course grade. Interestingly, there was a lot of similarity across the latter group (with the journal and report) in the answer to the exam question from the A through the D students. Although the A students were somewhat better at "stepping back" to think about the process itself and to de-personalize their roles, all students understood that process and performance can seriously affect content. The poorer students in the course also ran much higher marks on the policy exercise assignments and related exam question than on the regular course assignment given prior to the policy exercise or its assignments. It would appear that all students benefited more from the policy exercises if they were given time for reflection on their meaning, but the weaker students benefited most of all. Although this is preliminary, it does indicate the need for more research on the effects of this type of learning. 


\section{Conclusion}

Performance skills matter. Students worry about them. Like all adults, they will need to perform in public forums throughout their life and they are performing now in their classrooms or tutorials - or failing to. Performance affects their learning, both in their educational settings and in their capacity to understand the dynamics of social and political engagement. We would do well as educators to pay more attention to this. This study has investigated student's perceptions and feelings around their own class performance in relation to other students and their instructor, as well as with regard to process outcome as it may exist in the real world of policymaking. Students range broadly in any given classroom in their ability to perform. Many require mechanisms to improve their performance, whether they are under-performing or even sometimes over-performing. This paper presents one set of mechanisms with which to both implement and assess performance skills and performance learning.

Although there is a considerable body of research indicating the advantages of role playing for students, there is also some critique of its efficacy. This paper argues that this type of experiential teaching is being unfairly held up to traditional standards of knowledge as measured by traditional assessment tools. It need not be "better" than existing modes of teaching to be of use for many students, and as Chad argues this critical literature may underestimate the problem of design flaws in the existing methods of role playing (2012). In the experiential exercises presented here, participation is mandatory, structured, progressive and monitored - unlike ad hoc classroom debates and in tutorials. Plus individual participation is progressive from individual research to one-on-one communication and cooperation, to increasing numbers and complexity involving more series of negotiations, and finally to large forum debate and decision-making. Student performance skills are monitored by mandatory lists, tables, journals, reporting, as well as the instructor's presence and evaluation rubrics for the key performance events. None of these are onerous instructor workload items, and can be introduced progressively over the years as an instructor feels increasingly secure about them. There is reward for both students and instructors in the variety and fun it adds to the classroom. It also acts as a learning tool for the instructor. Many of us have little idea of what our students are experiencing in discussion groups. Often the comments made by the students in their journals reflect the difference between the instructor's perceptions of what is happening in classrooms and tutorials and the student's perspectives of the same.

This study highlights the importance of allowing students time for reflection, time to "get it", through staged learning and thinking in journals or reports designed into the policy exercises. Students' knowledge (based on final grade outcomes) improved if they were given time for reflection, and the weaker students benefited most of all, but just as importantly, they were given time to both work on their own performance skills and come to a greater understanding of the role of those skills play in our larger society. This study highlights the importance of student exposure to concepts and dynamics such as informal relations, participation, power, discourse, listening, rhetoric, expertise, and the emotional and irrational aspect of public engagement and decision-making in both the classroom and the social and political 
environment. When policy exercises are used to illustrate the dynamics of performance, process and content, students can better see why "policy is really hard." Students say they "underestimated the human factors" and "overestimated the role of knowledge and expertise in policy making." It helps them to balance the rationality and predictability of the textbook version with the uncertainty, power relations and human factors of the lived experience. It "brings the policy process beyond the pages of a book into a more personal realm" where it can help develop interpersonal professional skills such as comportment, hermeneutical attention and empathy, listening, negotiating, conflict resolution, knowledge acquisition and solution finding. It allowed students to gain knowledge about i) performance dynamics and their effects on human interaction and outcomes, ii) process dynamics and the limitations they place on roles and outcomes, and iii) content dynamics around a specific public policy issue. Performance is not just a useful skill; it is a necessary skill; we need to make more effort to understand and support it. We need more investigation into this dynamic, whether in experiential learning or everyday classroom and tutorial engagement.

\section{References}

Austin, W. Chadwick, Todd McDowell \& David H. Sacko. (2006). Synergy across the curriculum: Simulating the institution of postwar Iraqi government. Journal of Political Science Education, 2(1), 89-112. http://dx.doi.org/10.1080/15512160500484119

Baranowski, Michael. (2006). Single session simulations: The effectiveness of short congressional simulations in introductory American government classes. Journal of Political Science Education, 2(1), 33-49. http://dx.doi.org/10.1080/15512160500484135

Bolling, Anna. L. (1994). Using group journals improve writing and comprehension. Journal of Excellence in College Teaching, 5(1), 47-55. Retrieved from http://www.compact.org/resources/journal-of-excellence-in-college-teaching/955/

Cavanagh, Michael. (2011). Students' experiences of active engagement through cooperative learning activities in lectures. Active Learning in Higher Education, 12(1), 23-33. http://dx.doi.org/10.1177/1469787410387724

Chasek, Pamela. (2004). Power politics, diplomacy and role playing: Simulating the UN Security Council's response to terrorism. Presented at the Annual Meeting of the International Studies Association, Montreal, Canada.

Cherney, Isabelle D. (2008). The effects of active learning on students' memories for course content. Active Learning in Higher Education, 9(2), 152-71. http://dx.doi.org/10.1177/1469787408090841

Coninx, Neal, Karel Kreijns \& Wim Jochems. (2012). The use of keywords for delivering immediate performance feedback on teacher competence development. European Journal of Teacher Education, 35, 11-19. http://dx.doi.org/10.1080/02619768.2012.717613

De Grez, Luc, Martin Valcke \& Irene Roozen. (2012). How effective are self- and peer 
assessment of oral presentation skills compared with teachers' assessments? Active Learning in Higher Education, 13(2), 129-142. http://dx.doi.org/10.1177/1469787412441284

Dougherty, Beth K. (2003). Byzantine politics: Using simulations to make sense of the Middle East. Political Science and Politics, 36(2), 239-44. http://dx.doi.org/10.1017/S1049096503002154

Fliter, John. (2009). Incorporating a sophisticated Supreme Court simulation into an undergraduate Constitutional law class. Journal of Political Science Education, 5(1), 12-26. http://dx.doi.org/10.1080/15512160802611955

Frederking, Brian. (2005). Simulations and student learning. Journal of Political Science Education, 1, 385-93. http://dx.doi.org/10.1080/15512160500261236

Galatas, Steven E. (2006). A simulation of the Council of the European Union: Assessment of the impact on student learning. Political Science and Politics, 39(1), 147-51. http://dx.doi.org/10.1017/S104909650606029X

Lu, Chunlei \&Wenchun Han. (2010). Why don't they participate? A self-study of Chinese graduate students' Classroom Involvement in North America. Brock Education, 20(1), 80-96. Retrieved from http://brocked.ed.brocku.ca/

Gleason, James P., \& Jayne L. Violette. (2012). Integrating service learning into public relations coursework: Applications, implications, challenges, and rewards. International Journal of Teaching and Learning in Higher Education, 24(2), 280-285. Retrieved from http://www.isetl.org/ijtlhe/

Grove, Andrea. (2005). "Simulating global politics, stimulating students: Pretending to make introductory IR courses more 'Real'." Presented at the Annual Meeting of the International Studies Association, Honolulu, Hawaii.

Hayati, Majid. (2006). Take 2, Act 1: Feeding two birds with one scone!: The role of role playing in teaching english. Arts and Humanities in Higher Education, 5(2), 209-19. http://dx.doi.org/10.1177/1474022206060000

Johns, Carolyn M., Patricia L. O'Reilly \& Gregory J. Inwood. (2007). Formal and informal dimensions of intergovernmental administrative relations in Canada. Canadian Public Administration, 50(1), 21-41. http://dx.doi.org/10.1111/j.1754-7121.2007.tb02001.x

Jones, Rebecca. (2008). Evaluating a cross-continent EU simulation. Journal of Political Science Education, 4, 404-34. http://dx.doi.org/10.1080/15512160802413790

Kahn, Melvin. A., \& Perez, Kathleen. M. (2007). "The game of politics simulation: An exploratory evaluation." Presented at the Annual Meeting of the American Political Science Association. Chicago, IL, U.S.A

Krain, Matthew, \& Lantis, Jeffrey S. (2006). Building knowledge? Evaluating the effectiveness of the global problems summit simulation. International Studies Perspectives, 7, 395-407. http://dx.doi.org/10.1111/j.1528-3585.2006.00261.x 
Lai, Emily R. (2011). Performance-based assessment: Some new thoughts on an old idea. Pearson Education Bulletin, 20, 1-4. Retrieved from http://www.pearsonassessments.com/hai/images/tmrs/Performance-based-assessment.pdf

Lay, Celeste J., \& Kathleen J. Smarick. (2006). Simulating a Senate office: The impact on student knowledge and attitudes. Journal of Political Science Education, 2(2), 131-46. http://dx.doi.org/10.1080/15512160600668967

Lean, Jonathan, Jonathan Moizer, Michael Towler \& Caroline Abbey. (2006). Simulations and games: Use and barriers in higher education. Active Learning in Higher Education, 7(3), 22-42. http://dx.doi.org/10.1177/1469787406069056

Micari, Marina \& Denise Drane. (2011). Intimidation in small learning groups: The roles of social-comparison concern, comfort, and individual characteristics in student academic outcomes. Active Learning in Higher Education, 12(3), 75-187. http://dx.doi.org/10.1177/1469787411415078

Moss, Bernard. (2000). The use of large-group role-play techniques in Social Work education. Social Work Education, 19(5), 472-83. Retrieved from http://www.tandfonline.com/toc/cswe20/current

Oros, Andrew L. (2007). Let's debate: Active learning encourages student participation and critical thinking. Journal of Political Science Education, 3, 293-311. http://dx.doi.org/10.1080/15512160701558273

Powner, Leanne. C., \& Allendoerfer, Michelle. G. (2008). Evaluating hypotheses about active $\begin{array}{llll}\text { learning. International Studies } & \text { Perspectives, } & \text { 9, }\end{array}$ http://dx.doi.org/10.1111/j.1528-3585.2007.00317.x

Rackaway, Chapman, \& Goertzen, Brent J. (2008). Debating the future: A social security political leadership simulation. Journal of Political Science Education, 4(3), 330-40. http://dx.doi.org/10.1080/15512160802202961

Schaap, Andre. (2005). Learning political theory by role playing. Politics, 25(1), 46-52. http://dx.doi.org/10.1111/j.1467-9256.2005.00228.x

Smith, Elizabeth T., \& Mark A. Boyer. (1996). Designing in-class simulations. Political Science and Politics, 29(4), 690-94. Retrieved from http://journals.cambridge.org/action/displayJournal?jid=psc

Stover, William. J. (2007). Simulating the Cuban Missile Crisis: Crossing time and space in virtual reality. International Studies Perspectives, 8, 111-20. http://dx.doi.org/10.1111/j.1528-3585.2007.00272.x

Thurlings, Marieke, Marjan Vermeulen, Karl Kreijns, Theo Bastiaens \& Sjef Stijnen (2012). Development of the Teacher Feedback Observation Scheme: evaluating the quality of feedback in peer groups. Journal of Education for Teaching: International Research and Pedagogy, 38(2), 193-208. http://dx.doi.org/10.1080/02607476.2012.656444 


\section{Macrothink}

International Journal of Education

ISSN 1948-5476

2013, Vol. 5, No. 1

Timostsuk, Inge \& Aino Ugaste. (2012). The role of emotions in student teachers' professional identity. European Journal of Teacher Education, 35(4), 421-433. http://dx.doi.org/10.1080/02619768.2012.662637

Van Assendelft, Laura., \& Diduch, Amy. (2007). The political economy of federal budgeting: An interdisciplinary simulation approach. Presentation at the Annual Meeting of the Southern Political Science Association, New Orleans.

Wheeler, Sarah M. (2006). Role playing games and simulations for international issues courses. Journal of Political Science Education, 2(3), 331-47. http://dx.doi.org/10.1080/15512160600840814

\section{Copyright Disclaimer}

Copyright reserved by the author(s).

This article is an open-access article distributed under the terms and conditions of the Creative Commons Attribution license (http://creativecommons.org/licenses/by/3.0/). 